WILLIAM SAYERS

Cornell University, Ithaca

ws36@cornell.edu

\title{
ETYMOLOGIZING DEPRECATORY REDUPLICATIVE COMPOUNDS OF THE TYPES FLIM-FLAM AND HIGGLEDY-PIGGLEDY (PART I)
}

Keywords: lexicogenesis, lexicography, compound words, etymology, disparagement

\begin{abstract}
Sample English reduplicative compounds on the model of flim-flam and higgledy-piggledy are analyzed for the interplay of formal features (alliteration, vowel alternation, rhyme), semantics (as parts and wholes), and obscure origins. Loans, new coinages, internal realignment, register, and affect are discussed. Inadequacies in earlier lexicographical, especially etymological, treatment are remedied.
\end{abstract}

Lexicogenesis in the Germanic languages includes the generation of compounds in which the two elements have phonological and semantic similarities. English, in particular, is rich in such formations, which may be grouped in two typological classes: 1) those with alliterating initial consonant(s) followed by a shift from front to back vowel in the generally similar second half of the compound, and 2) those with dissimilar initial consonant(s) but similar continuing and concluding sounds. The types are exemplified by flim-flam and higgledy-piggledy, which also illustrate the range from monosyllabic to polysyllabic elements, in this latter case forming a double dactyl, with a playful or dismissive affect. These compounds belong to the popular register of English and their semantics are frequently expressive of whimsy or obsessiveness, triviality, inconsequentiality, even duplicity and deceit. ${ }^{1}$

This is not universally true, as illustrated by zig-zag, first recorded in 1712, in which, in a kind of reverse rebus effect, the graphic contours of the initial $z$ 's and vowel alternation exemplify the abrupt changes of course designated by the word. 
Such reduplicative or reiterative compounds are then both descriptive, with these notions conveyed by the above formal features, and judgmental. Other compounds enter the force field created by this category of words and over time experience effects of alignment.

Deprecatory reduplicative compounds are not recognized as a class in standard lexicographical reference works. The Oxford English dictionary [OED], which will serve as point of reference in the following discussions, calls these variously rhyming compounds, vocal gestures, impressionistic creations, the products of onomatopoeia. The OED's entries for most of the words under consideration in this essay were drafted in the last decade of the nineteenth century and, by the dictionary's own admission, have not been fully updated. In this they suffer the benign neglect of popular speech generally, a reflection of earlier lexicographical pro- and prescriptiveness. In particular, efforts to establish satisfactory etymologies for the elements of the compounds (variously called slang, vulgar, obscene, jargon, or cant) are often perfunctory. As with the usage of the words themselves, attitude seems to have trumped analysis. ${ }^{2}$

This essay addresses five words that are true reduplicative compounds as described above, and a further three that display their influence in various way. All are without satisfactory etymologies. Other matters to be discussed are the non-phonological relations between the two elements of each compound and the roles of lexical loans and fresh coinages.

Fiddle-faddle In an entry first published in 1893 and not yet fully updated, the OED defines fiddle-faddle as 'trifling talk or action; an idler, trifler; a gossip, chatterbox' (OED, s.v. fiddle-faddle). The nominal use is attested from 1577 and the adjectival from a half-century later. Verbal use as 'to be busy about petty trifles' also follows early in the seventeenth century. As concerns etymology, the $O E D$ focuses on form rather than signification:

This and the verb are reduplications with vowel variation of fiddle $\mathrm{n}$. or faddle $\mathrm{n}$;; compare German fickfack, and contemptuous formations like flim-flam, skimbleskamble, etc.

In the separate entry for fiddle, the dictionary groups a number of meanings and applications under a headword that designates the musical instrument. The origin of the name lies in a putative Old English ${ }^{*}$ fiðele (Middle English fibele). Yet, despite listing such figurative applications of fiddle as for a watchman's rattle, the sixteenth part of a pound sterling, a swindle, and as an abbreviation of the interjection Fiddlesticks!, the dictionary offers no instance of a base word fiddle, noun or verb, having any of the semantic or affective features that would be evoked in coining the

2 For a review of the theory and praxis of English etymology on the book-length scale over the last century and a half, see, in a sister publication, Considine (2015). 
disparaging reduplicative compound fiddle-faddle, with the possible exception of to fiddle in the sense 'to make aimless or frivolous movements; esp. to play, toy about, at, on, over, with (a thing, rarely, a person); to act idly or frivolously' (OED, s.v. fiddle). Although less than explicit, the OED would have readers accept that fiddle-faddle was composed on a basis of fiddle in the non-musical sense of attending to trifles. Despite the repetitive and highly visible bow action low on the strings and finger action on the neck, one wonders why playing this cousin of the violin should have been singled out as symbolic of inconsequential fussiness. To paraphrase the OED, fiddle-faddle is a reduplicative compound formed on the basis of a discrete word that already had the common formal features of geminate internal consonant and -le suffix seen in many other semantically comparable words. In a separate entry, the second element, faddle, is called dialectal or colloquial, and is sparingly attested. It is defined as 'nonsense, trifling; usually fiddle-faddle n., adj. and int.' and is not accompanied by etymological commentary. ${ }^{3}$

In the following, the possibility of an alternative historical course for fiddle-faddle is explored. Three sets of questions guide this inquiry, contentual, temporal and spatial: how do the two members of the compound relate to one another semantically? which of fid-fad or fiddle-faddle is to be viewed as the more "original" form? and what is the relationship between the evidence of standard English and that drawn from the variety of English dialects? Among the attendant difficulties are the limited phonic matter of the monosyllables fid and fad, the absence of known etymologies, and the comparable lack of historical depth of many of the significations or uses of the words in question. All too often, attestations are late. With no clear sources in Old English for either fid or fad, one is wary of invoking even more remote Germanic antecedents.

To turn first to possible antecedents of the second element of the compound, fad was used of a bundle of straw, as well as in reference to personal obsessiveness and vogue activities. In English dialect, fad could also have reference to a 'whim' or 'fancy' but as a verb meant 'to busy oneself with trifles' or 'to deceive'. It was also used of making much of a child (cf. dandle and the possible influence of fondle; Wright 1898-1905: 2.274-275, s.v. fad.). As for the possible antecedents of fiddle other than as the instrument name, fid is present in English as the designation for a small, thick piece of something (from 1615; OED, s.v. fid; Wright 1898-1905: 2.347 , s.v. $f i d$ ). At sea, the fid is a tapered wooden pin like a marling spike, used in repairing ships' lines. Other technical applications also focus on the fid as a small key piece in a mechanical assembly. Although the OED lists only the nautical application for fid as a verb, The English dialect dictionary [EDD] offers a number of meanings, among which 'to cause to move one way and the other with quick alternations; to work hard at anything'. In dialect use, a longer form, fiddle, meant 'to dawdle, waste time, move about aimlessly' but also 'work in concentrated

3 In a separate entry, not cross-referenced in that for fiddle-faddle, fidfad (in print by 1754) is defined as 'one who gives fussy attention to trifles; a petty matter of detail, a crotchet; frivolous, fussy, petty', and is explained as 'short for fiddle-faddle'. 
fashion at something (often a detail)'. To fiddle, like the verb to fid, was also used of moving from side to side, and in Scotland was used of the wagging of a sheep's tail (DSL 2014, s.v. fiddle). If we allow the idea of fiddle as an augmented form of fid ( fid with geminate consonant plus the verbal suffix -le, indicative of reiterated action) and not as a figurative use of the instrument name, we may judge some of the OED's meanings for fiddle better listed under a separate headword that is recognized as an augmented form of fid.

More explicitly, it is proposed that non-musical fiddling is not a figured adaptation of the action of the fiddler's hands or of the value attached to the music itself. Interestingly, in his English-French dictionary of 1530 John Palsgrave distinguishes, orthographically and semantically, between playing the instrument ('I fyddell') and busying oneself with one's hands ('I fydell'): 'Loke you fydell nat with your handes whan your maister speketh to you' (Palsgrave 1530: 549, col. 1). Nonetheless, use of the verb to fiddle 'to fuss' in mainstream English must have been affected by associations with the musical instrument and the semantic shift or perceived correspondence may be attributed to a process comparable to folk etymology. Two centuries after Palsgrave, Dr. Johnson sees fiddle-faddle as reflecting the musical instrument but also writes of rapid hand movements. He identifies the compound in his dictionary as 'cant' but this is more likely a reference to register than a statement on origin (Johnson 1755, s.v. fiddle-faddle). Also of interest is the extension from body movement, e.g. fiddling with one's hands or clothes, to speech as also exemplified in such equivalents of fiddle-faddle as fiddlesticks! 'nonsense!' (1600) and the dismissive fiddledeedee (1784).

Although, as earlier noted, there are no obvious sources for fid in Old English, Old Norse knew the verb fitla 'to finger, fidget'. Here we seem to have the closest antecedent of English fid/fiddle. Speculatively, one might also adduce Old Norse fitja 'to web' or 'knit together' (Cleasby et al. 1957, s.v. fitja). The noun form fit references the webbed foot of a duck or a seal's flipper, while the verb entails close work with the hands. The English noun fid may then have originally designated something hand-sized, to be worked on. This correspondence encourages us to consider Norse as a source for fad/faddle. Only faðma 'to embrace, grasp in one's arms' suggests itself (and the - $m$ - is part of the stem), but is a plausible source for English fad as a bundle or armful of straw. More figuratively, it could have been used of taking up a personal cause or interest, busying oneself with trifles.

It then appears that, despite subsequent associations, fiddle-faddle does not originate in any particularly appropriate correlation between the playing of the instrument (e.g. the 'fussy' movement of the player's hands) or the social worth of fiddle music but rather in the amplified form of the verb to fid. Faddle, possibly without prior independent status, is the formally appropriate complement to fiddle, with consonant alliteration and a shift in the vowel from front to back. Yet it may have an independent origin in a loan from Old Norse in the Danelaw or North Sea port towns in Britain, as seems to be the case for fid/fiddle. The putative Norse antecedents are both hand-related, although there is no close connection. Conjoined in Britain in simple ( fid-fad) or augmented ( fiddle-faddle) form, they became complementary. 
Norse connections would soon have been lost, while fiddle subsequently oriented itself semantically toward the name of the musical instrument.

In this and other derogatory reduplicative compounds, the high front vowel generally followed by a low back vowel creates both a falling effect in simple phonics and, in terms of phono-semantics and affect, an impression not only of continuous or repeated activity but also of inconstancy, inconsequentiality, and triviality. Similar effects are obtained through variation of the initial consonant or consonant cluster, and duplication of the remainder of the initial word in the other major class of reduplicative compounds, as exemplified by higgledy-piggledy, to which the discussion now turns.

Higgledy-piggledy In an entry from 1898 the OED defines higgledy-piggledy in its adverbial use as 'without any order of position or direction; in huddled or jumbled confusion and disorder; with heads and tails in any or every direction' (OED, s.v. higgledy-piggledy). The commentary on etymology is worth reproducing in full, for the light it throws on lexicographical assumptions and practice at the time of publication:
A rhyming compound of obscure origin. Mainly an example of 'vocal gesture', the odd conformation of the word answering to the thing described; whether founded on pig, with some reference to the disorderly and utterly irregular fashion in which a herd of these animals huddle together, is uncertain, though examples show that such an association has often been present to persons using it. If the collateral higly- pigly adv. and adj. were the original form, the sequence pig, pigly, higly-pigly would be not unlikely.

The OED shows an awareness of the process of folk etymology (piggledy $\sim$ pig) and might well have been more thorough-going and have linked higgledy to hog. But the metaphor of 'vocal gesture' does little to advance the pursuit of lexicogenesis. The astute late sixteenth-century linguist, translator, and lexicographer John Florio shows an appreciation of meaning, form, and register when he assembles the run 'pelmell, helterskelter, higledi-pigledie' (Florio 1598, as given in $O E D$ ). In another entry he has 'snatchingly, higledi-pigledie, shiftingly, nap and run'. There is a sense of both disorder and movement, the latter precluding any effort at cognitive organization.

These reduplicative, reiterative compounds favour affect over analysis. In many cases it would seem that the nucleus of original signification lies in the first element of the compound. Were this true, the etymological clue in the present instance would be sought in higgle; porcine associations could have been evoked in the coining of the second term or in the subsequent use of the compound, as the OED suggests.

In its entry for higgledy-piggledy, the OED makes no reference to the verb higgle, for which it otherwise offers two related definitions: 1) 'to cavil or dispute as to terms; to stickle; esp. to strive for petty advantages in bargaining'; 2) 'to buy up a commodity, hoping to sell it elsewhere or at another time for profit' (paraphrase). 
The first signification has clear affinities with the more current haggle, illustrating the vowel alternation mentioned above. Common to both uses of higgle are the dual points of reference: the asking and bidding prices and their successive readjustments on the one hand, present and future value/price on the other. This recalls some of the reiterating effects of higgledy-piggledy but not the disorder, unless the second element is intended to have a negating effect. It should then come as little surprise that the form heegle-haggle is met in Scots, although it may be a once-off, late nineteenth-century coinage (Grant 1931-1975, s.v. heegle-haggle). On balance, however, the give and take of higgling does not offer a convincing match with the disorder of higgledy-piggledy.

To turn now to piggle and related as the less likely nucleus of the phrase in question, the relevant verb has two meanings: 1) 'to fiddle or toy with; to niggle or worry at'; 2) 'to uproot; to pick or scrape at' (OED, s.v. piggle). Both incorporate the reiterative effect seen in higgle and, indeed, in verbs ending in -le. The etymology is called "uncertain", although it is speculated that the form is an alteration of niggle. There is no suggestion of the disorder conveyed by higgledy-piggledy.

From among native English roots that might be invoked in this investigation, the verb hig is not found in standard English but in dialect is a variant of higgle in the sense of bargaining (Wright 1898-1905: 3.156-157, s.v. hig). This recalls the OED evidence for higly-pigly in the sense of randomly, and without pattern or order in a citation from 1664, thus somewhat later than Florio's higledi-pigledie. The compound prompts speculation on an originally objective, as distinct from impressionistic, formulation, hogly-pigly, which surrendered its semantic transparency (leaving to one side for the moment which specific qualities of the animal are in question) in favour of an assumption of the strictly formal features of initial consonant variation and coincidence in the remainder of the word, formal features that nonetheless had a strong affective value. Whether higly-pigly or hogly-pigly, this would entail the loss of the repetitive sense created by the verbal suffix -le. Furthermore, English dialects knew another hig, this as a noun. Derived from Old English hyge 'mind, thought, intention, determination, purpose', hig experienced a semantic narrowing so that the meaning 'passion, sense of offence' emerged (cf. higged 'angry'). ${ }^{4}$ To turn to the other relevant simplex, pig also had multiple significations in the dialects of Great Britain. Relevant here is to pig 'to herd or crowd together; sleep more than one in a bed, have crowded uncomfortable quarters' (Wright 1898-1905, 4.495, s.v. pig). If this hig and this pig are behind the elements of higly-pigly, it would conjoin a mental state with a physical one: a situation both agitated and crowded.

To stand back a moment from this welter of possibilities, an excursus is made into Old French and to a word that through a number of transformations might conceivably have led to higgledy-piggledy. Gallo-Romance adapted the adjective snel 'rapid' from Frankish, a Germanic language of the Rhineland (cf. German schnell; von Wartburg et al. 1922-2002: 17, 159b, s.v. ${ }^{*}$ snel). Early French added an epenthetic initial vowel $e$-, which led to the form isnel but also ignel. The latter word

4 Hig with this meaning is not noted in the OED. 
is well attested in French, Norman, and Anglo-French, as is the adverb ignelement (Rothwell et al. 2005, s.v. ignel). This could have been partly loaned and partly calqued (-ment replaced with $-d y$ ) into early English as igledy (although no ready reason can be found for the suppression of the $-n$-) with the meaning 'in rapid, rushed fashion'. Two further developments would have been needed in order to yield higgledy-piggledy: a semantic shift from hurriedness to resultant disorder and the invention of a complementary second element for a compound on the popular model. Such a hypothetical later development may have been furthered by the presence in Old French of an intensive form with initial p-, parigneler 'to rush'. Also to be noted are the forms ignelepas, a compound with pas 'pace, step', and igneleté 'rapidity'. The last-named is closest to higgledy but caution must be taken in pairing the nominal abstract suffix (-té) of Old French with the adverbial suffix of English (-dy). The source would account for the sense of rapid movement apparent in John Florio's early string of synonyms. This French connection, however, lacks conviction when compared to possible native English sources.

From among the options reviewed above, hig 'state of agitation' and pig 'crowding' are judged the most plausible antecedents of higly-pigly and represent the union of two discrete and independent elements, rather than a second one chosen with reference to, or modeled on, the first. Even at the stage of higly-pigly, formal similarities are prominent in that only the initial consonant differs between the words, with both completed with adverbial suffixes of manner. The development to higgledypiggledy entails secondary phenomena, the basic duality being further melded and intensified through the double use of the reduplicative and reiterative verbal suffix -le. Also added is a second adverbial ending (- $-d y)$ for an extended rhyming effect. Porcine associations were long maintained, chiefly through the -pig-element.

If this history of higgledy-piggledy wins any credence, it illustrates that this familiar form of reduplicative compound - a form rather more complex than the $O E D$ 's 'vocal gesture' - is open to rewarding etymological scrutiny, a scrutiny perhaps often facilitated in greater measure by the archive of English dialect represented by Wright's English dialect dictionary than by the venerable Oxford English dictionary, the supposed repository of ALL the English words. From the disarray of higgledypiggledy attention turns to a term for willed confusion and deception.

Flim-flam The $O E D$, in an entry from 1897 and not yet fully updated, defines flimflam as 'a piece of nonsense or idle talk; a trifle, a conceit; a paltry attempt at deception' (OED, s.v. flim-flam). In the second of these significations, the form is attested as early as the first half of the sixteenth century: 'He and his fellawes were sent hither ... but for a flim flawe to stoppe the ymagination of the Kynge and Counsaile in that behalf.' ${ }^{5}$ In addition to its intrinsic interest, the etymological commentary shows

5 Reproduced from the $O E D$, where the original text is identified as State papers (during the reign of) Henry the eighth (1830-1852: II. Iii. 552). 
an awareness of both formal and contentual features, of the effects of both analogy and languages in contact:

One of the many onomatopoeic reduplications with vowel variation expressive of contempt; compare fidfad, skimble-skamble, whimwham. Possibly based on a Scandinavian word which may have existed in some English dialects; compare Old Norse flim a lampoon, flimska mockery, flimta to flout.

The objective of the present note is to determine the relative weights of formal criteria and semantics, and of the first and second elements, respectively, in the coining of the compound. It will be noted that the OED's proposed etymology singles out the first element. Is the second to be understood as a mere phonological variant required in the creation of such reduplicative compounds?

In the following, the image of a stage set, both insubstantial and illusionary, is proposed as a backdrop to the discussion. The OED has two entries for flim: as an equivalent of flam (a single attestation) in the sense of a fabrication, falsehood, piece of deception, and as a slang term for a $£ 5$ note (OED, s.v. flim). No etymology, independent of that for flim-flam, is offered. The EDD offers a fuller spectrum. Flim is noted as an obsolete Scots term for 'whim' or 'illusion', while flim as an adjective meant 'pliable, limp' - flimsy, one might say (cf.flimp as limp). Flim-flae (again Scots) is identified as 'flattering speech', and flim-flam is defined in Scots dictionaries as 'idle talk, nonsense' (Wright 1898-1905: 2.405, s.v. flim-flam; Grant 1931-1975, s.v. flim-flam). To pursue the clue offered in the juxtaposition of flim and limp, the OED entry for flimsy is 'destitute of strength or solidity; easily destroyed; slight, frail, unsubstantial'. The word is relatively late (eighteenth century) and the dictionary speculates on 'an onomatopoeic formation suggested by film'.

Although never a common term, English flimmer is explained as 'to burn unsteadily' $(O E D)$ and is then a near-synonym of glimmer and flicker. Flimmer has Germanic origins; cognates are Norwegian flimre and German flimmern with the same meaning. The $O E D$ definition gives prominence to the quality of the light emitted rather than its effect on viewers. Associating flim with flimmer immediately makes more comprehensible the Scots use of this word as 'mist rising from the ground' than does any recourse to the word film as proposed by the OED (DSL 2014, s.v. flim). The term conjures up a combination of reduced visibility and insubstantiality. The natural phenomenon of fog or mist has a figured counterpart in willed deception and illusion. With flim established as a light phenomenon, possibly leading to misperception, we turn to its complement, flam (Wright 1898-1905: 2.380-381, s.v. flame).

The OED has entries for flam as both noun and verb, with a basic signification of 'fanciful notion, deception' (DSL, s.v. flim). ${ }^{6}$ The two entries make reference each to the other but no true etymological explanation is offered, unless flam is to be seen as an abbreviation of flim-flam, which simply displaces the immediate question of origins. The $E D D$ lists flam in these same senses but also has the meanings

6 OED, s.v. flame; the related flamb 'to baste with hot lard, etc.' might also be considered, since this would produce intermittent flame and light effects, as do glimmer, glitter, etc. 
of a sudden gust of wind, a violent blow, low marshy ground, flame, and a broadbrimmed hat - few of which might advance present purposes (Wright 1898-1905: 2.380-381, s.v. flame). The earlier cited flimmer might, however, suggest that flame were behind English flam, with the vocalic variation between flim and flam (i/a) reflecting the scale of the light effects. Flame could mean 'to kindle, enthuse', and thus refer to the acquiescence of the dupe of flim-flam. Speculatively, one might suggest that the high front vowel of flim references the wily deception, the lower back vowel of flam, its recognition and exposure. Nonetheless, it might be more prudent to see in flam a formally generated counterpoint to flim, that is, the means to meet the requirement of vowel variation in the compound (other possibilities would have been flem, flom, flum). In the matter of other correspondences, flimflam would cause other formally and semantically related terms to resonate in the speaker's and listener's inner ears. ${ }^{*}$ Glimmer-glamour is, of course, an ad hoc construct but embodies much of what is understood by flim-flam, although it is not such a neat phrasing as hocus-pocus. ${ }^{7}$ Other echo effects proceed from sham and, to a contemporary hearer, scam.

The discussion thus far has followed parameters established by the $O E D$ and its choice of flim-flam as headword for the relevant entry, apparently on the basis of its historical dominance in usage. Yet, at this juncture it may be advisable to return to the earliest evidence, in particular the reference in state papers from the reign of Henry VIII of flim flawe used of a deceptive political manoeuver. The OED has a full entry for flaw that includes the basic meanings of both 'a detached piece of something' and 'a breach, broken or faulty place'. (Although the dictionary is not explicit in this regard, a semantic progression may be observed: from detached piece to the locus of the detachment on the parent body, now seen as a defect.) Flaw was used in the first sense of a flake, as of snow, but also of the spark from a fire. The OED looks for an origin for the word in Old Norse and sees flake as a related term. ${ }^{8}$ If the second element of flim-flaw meant a spark of fire, we should have a pair of luminous terms for transient, fire-related optical phenomena: glimmer and spark. This sense of flaw seems not to have been continued past the sixteenth century (see the evidence in the $O E D$ ). Concurrently, or perhaps in some kind of causal relationship, the compound shifts from being semantically reduplicative (glimmer + spark) to phonologically reduplicative (flim-flam). Eventually, the notion of light phenomena is also lost, although the newly refigured compound retains its sense of transience, intermittence, unsure cognitive experience, and, in a moral dimension, condemnable duplicity.

In summary, flim-flam is a typical reduplicative compound in form. In its semantics, too, it shares the disparaging affect of such collocations. Rather than having an origin in onomatopoeia or early Norse words for mockery and satire $(O E D)$, the first element originally referenced potentially seductive or deceptive light effects (flimmer)

An etymological note on the word glamour is in preparation by the author.

8 See the OED's extensive etymological commentary accompanying the entry for flake, n. ${ }^{2}$ but also the cautionary note: 'This entry has not yet been fully updated (first published 1896)'. 
but also became associated with insubstantiality (cf. flimsy). Flam is traceable to an “original" flaw 'spark' but was later reconfigured as a variant on flim. Like the painted stage set, flim-flam is both illusory and insubstantial - glitz but no gold. This essay concludes with a second part in a future issue of the journal.

\section{References}

Cleasby R., Vigfússon G., Craigie W.A. (eds.). 1957. An Icelandic-English dictionary. [2 $2^{\text {nd }}$ edition]. Oxford.

Considine J. 2015. English guides to etymology from Skeat to Durkin. - Studia Etymologica Cracoviensia 18: 9-40.

DSL = Dictionary of the Scots language. 2014. [http://www.dsl.ac.uk].

$E D D=$ Wright 1898-1905.

Florio J. 1598. A worlde of wordes, or most copious, and exact dictionarie in Italian and English. London.

Grant W. (ed.). 1931-1975. The Scottish national dictionary. [= SND]. Edinburgh.

Johnson S. 1755. A dictionary of the English language. London.

OED = Oxford English dictionary. OED online. 2016. [http://www.oed.com].

Palsgrave J. 1530. Lesclarcissement de la langue francoyse. London.

Rothwell W. et al. (eds.). 2005. Anglo-Norman dictionary. [= AND; $2^{\text {nd }}$ edition]. London.

von Wartburg W. et al. (eds.). 1922-2002. Französisches etymologisches Wörterbuch. [= FEW]. Bonn.

Wright J. (ed.). 1898-1905. The English dialect dictionary. [= EDD; 6 vols.]. London. 